\title{
Effects of thickness of substrate and spacing on growth and yield of Limnophila rugosa (Roth) Merr. under organic-oriented farming
}

\author{
Duong T. T. Pham*, Hung T. Huynh, \& Thinh V. Tran
}

Faculty of Agronomy, Nong Lam University, Ho Chi Minh City, Vietnam

ARTICLE INFO
Research Paper
Received: May 10, 2018
Revised: June 28, 2018
Accepted: August 09, 2018
Keywords
Limnophila rugosa (Roth) Merr.
Spacing
Substrate thickness
*Corresponding author
Pham Thi Thuy Duong
Email: pttduong@hcmuaf.edu.vn

\begin{abstract}
Limnophila rugosa (Roth) Merr. is an annual herb native to wetlands in Vietnam. It is widely cultivated and used as food flavoring, seasoning or culinary herb. While most studies examine the essential oil of Limnophila rugosa, reports of cultivation practices such as substrates and spacing that may enhance the growth and yield of Limnophila rugosa is very limited. The objective of this study was to determine the appropriate thickness of the substrate and plant spacing for growth and yield of Limnophila rugosa under organic-oriented farming by using a completely randomized design (CRD) for the experiment. The results indicated that Limnophila rugosa performed the highest number of branches and plant fresh weight when it was grown at the substrate thickness of $20 \mathrm{~cm}$ in combination with spacing of $20 \times$ $15 \mathrm{~cm}$. However, the highest absolute yield $\left(6414,6 \mathrm{~kg} / 1000 \mathrm{~m}^{2}\right)$ was obtained at a spacing of $20 \times 10 \mathrm{~cm}$ combined with the substrate thickness of $20 \mathrm{~cm}$.
\end{abstract}

Cited as: Pham, D. T. T., Huynh, H. T., \& Tran, T. V. (2019). Effects of thickness of substrate and spacing on growth and yield of Limnophila rugosa (Roth) Merr. under organic-oriented farming. The Journal of Agriculture and Development 18(1), 35-43. 


\title{
Ảnh hưởng của độ dày giá thể và khoảng cách trồng đến độ sinh trưởng, năng suất quế vị (Limnophila rugosa (Roth) Merr.) canh tác theo hướng hữu cơ
}

\author{
Phạm Thị Thùy Dương*, Huỳnh Thanh Hùng \& Trần Văn Thịnh \\ Khoa Nông Học, Trường Đại Học Nông Lâm TP. Hồ Chí Minh, TP. Hồ Chí Minh
}

\section{THÔNG TIN BÀI BÁO \\ Bài báo khoa học \\ Ngày nhận: 10/05/2018 \\ Ngày chỉnh sửa: 28/06/2018 \\ Ngày chấp nhận: 09/08/2018}

Từ khóa

Cây quế vị

Độ dày giá thể

Khoảng cách trồng

*Tác giả liên hệ

Phạm Thị Thùy Dương

Email: pttduong@hcmuaf.edu.vn

\section{TÓM TẮT}

Cây quế vị thường mọc hoang dại trong tự nhiên ở những nơi ẩm ướt và được trồng phổ biến để sử dụng như loại rau gia vị. Mặc dù có nhiều nghiên cứu về hàm lượng tinh dầu trong cây rau quế vị, nhưng rất ít nghiên cứu đề cập đến kỹ thuật canh tác như độ dày giá thể và khoảng cách trồng. Mục tiêu của nghiên cứu là nhằm xác định được độ dày giá thể và khoảng cách trồng thích hợp cho cây rau quế vị sinh trưởng tốt và đạt năng suất cao trong điều kiện canh tác theo hướng hữu cơ. Thí nghiệm hai yếu tố được bố trí theo kiểu hoàn toàn ngẫu nhiên $(\mathrm{CRD})$ với 3 lần lặp lại. Yếu tố thứ nhất gồm 3 độ dày giá thể $(25 \mathrm{~cm}, 20 \mathrm{~cm}, 15 \mathrm{~cm})$; yếu tố thứ hai gồm 3 khoảng cách trồng $(20$ $\times 20 \mathrm{~cm}, 20 \times 15 \mathrm{~cm}, 20 \times 10 \mathrm{~cm})$. Kết quả thí nghiệm cho thấy độ dày giá thể $20 \mathrm{~cm}$ kết hợp với khoảng cách trồng $20 \times 15 \mathrm{~cm}$ cho cây quế vị có số cành (22,6 cành/cây) và trọng lượng cây tươi (66,7 g/cây) cao hơn các tổ hợp còn lại trong thí nghiệm. Tuy nhiên, cây quế vị đạt năng suất thực thu cao nhất $6414,6 \mathrm{~kg} / 1000 \mathrm{~m}^{2}$ tại độ dày giá thể 20 $\mathrm{cm}$ với khoảng cách trồng là $20 \times 10 \mathrm{~cm}$.

\section{1. Đặt Vấn Đề}

Cây quế vị (Limnophila rugosa (Roth) Merr.) thường mọc hoang như cỏ dại trên các bờ ruộng hay nơi ẩm ướt, từ xưa con người đã biết sử dụng quế vị như một loại rau tự nhiên. Cây quế vị có vị cay nồng, tính bình giúp thanh nhiệt, giảm ho và các cơn đau. Ở nhiều nước, cây quế vị được xem là một loại thảo dược tốt cho sức khỏe, chữa bệnh suy nhược, trị cảm lạnh, đau họng (Tanaka \& Nguyen, 2007). Theo Acharya \& ctv. (2014), dung dịch chiết xuất từ cây quế vị có chứa flavonoid với hoạt tính kháng khuẩn. Hiện nay, nhu cầu sử dụng quế vị trong các món ăn ngày càng cao nên sản lượng thu hái trong tự nhiên không đủ để cung cấp, do đó quế vị đang được canh tác trên diện rộng như một loại cây trồng mang lại hiệu quả kinh tế cho người nông dân.

Theo Olle \& ctv. (2012), giá thể có ba chức năng chính là cung cấp không khí và nước, cho phép rễ phát triển tối đa và đáp ứng các tính chất vật lý cho cây trồng. Trồng cây trong giá thể giúp bộ rễ thông thoáng, do đó cung cấp đủ oxy cho vùng rễ nên cây phát triển khỏe mạnh. Việc xác định độ dày giá thể thích hợp tạo điều kiện thuận lợi cho rễ cây phân bố giúp cây trồng sinh trưởng tốt đồng thời tiết kiệm chi phí sản xuất. Bên cạnh đó, khoảng cách trồng quyết định mật độ phân bố của cây trên một đơn vị diện tích, tác động của mật độ cây trồng chủ yếu là do sự khác biệt trong phân bố năng lượng bức xạ mặt trời và tăng hấp thụ bức xạ mặt trời sẽ dẫn đến tăng hiệu suất quang hợp. Nguyen (2015) cho rằng, việc bố trí mật độ hợp lý giúp cây trồng tận dụng năng lượng ánh sáng mặt trời, hạn chế sâu bệnh hại, tạo tiền đề năng suất cao. Ngoài ra, mật độ thích hợp còn tiết kiệm được cây giống, công lao động và các chi phí khác góp phần nâng cao hiệu quả kinh tế. Mỗi giống cây trồng cần được bố trí ở khoảng cách hợp lý để đạt năng suất cao. Gieo trồng dày quá hoặc thưa quá đều ảnh hưởng đến sinh trưởng và năng suất cây trồng, đồng thời cũng ảnh hưởng đến sự phát sinh, phát triển của sâu bệnh, cỏ dại (Vo \& ctv., 1998; Pham, 2009). Ngoài ra, khoảng cách ảnh hưởng đến dư lượng nitrate trong cây trồng một cách rõ ràng (Samith 
\& ctv., 2010).

Tại Việt Nam cũng như trên thế giới có rất ít nghiên cứu liên quan đến kỹ thuật canh tác cây quế vị. Vì vậy, thí nghiệm đã được thực hiện nhằm xác định độ dày giá thể và khoảng cách trồng thích hợp cho cây rau quế vị.

\section{Vật Liệu và Phương Pháp Nghiên Cứu}

\subsection{Thời gian và địa điểm nghiên cứu}

Thí nghiệm được tiến hành từ tháng 11/2017 đến tháng 02/2018 tại Trại Thực nghiệm Khoa Nông học, Trường Đại học Nông Lâm TP.HCM.

\section{2. Điều kiện thí nghiệm}

Thí nghiệm được thực hiện trong nhà màng và che lưới đen phía trên để giảm $50 \%$ ánh sáng mặt trời. Nhiệt độ, ẩm độ và cường độ ánh sáng được ghi nhận vào các thời điểm 7,11 và 16 giờ hàng ngày. Trong đó, nhiệt độ và ẩm độ được đo bằng máy Anymeter TH602 - E được treo ở giữa khu thí nghiệm, cường độ ánh sáng đo bằng máy LX $1330 \mathrm{~B}$ tại 3 điểm cố định phân bố đều trong khu thí nghiệm. Trong thời gian thí nghiệm, nhiệt độ biến động trong khoảng $28,4-30,7^{0} \mathrm{C}$ và độ ẩm không khí nằm trong mức $66,5-70,5 \%$, cường độ ánh sáng dao động 434,8 - 614,3 Lux thích hợp cho sinh trưởng của cây quế vị.

\subsection{Phương pháp nghiên cứu}

\subsubsection{Vật liệu nghiên cứu}

Vật liệu phối trộn giá thể gồm phân trùn, mụn dừa và vỏ đậu phộng theo tỉ lệ $10 \%$ phân trùn $+60 \%$ mụn dừa $+30 \%$ vỏ đậu phộng. Trong đó, mụn dừa được ngâm trong nước vôi $10 \%$ trong 2 tuần và xả lại bằng nước sạch để loại bỏ chất chát; vỏ đậu phộng được phơi khô tự nhiên để loại bỏ các nấm mốc.

Giống quế vị có nguồn gốc tại huyện Trảng Bàng, tỉnh Tây Ninh, hom giống được thu thập là hom không có ngọn, khỏe, không bị sâu bệnh hại, có 4 mắt lá.

Bồn trồng có kích thước dài $\times$ rộng $\times$ cao là $3 \mathrm{~m} \times 1 \mathrm{~m} \times 0,3 \mathrm{~m}$ (thế tích $0,9 \mathrm{~m}^{3}$ ), bồn được đào sâu cách mặt đất $20 \mathrm{~cm}$ và đặt gạch cố định $10 \mathrm{~cm}$ phía trên, đáy bồn được lót bạt bằng nhựa dẻo chống thấm nước.

Phân bón được dùng trong thí nghiệm là phân bón lá hữu cơ DS80 được sản xuất bởi công ty
Canadian Humalite International INC. và phân phối bởi tập đoàn Lộc Trời. DS80 có chứa 72,6\% hữu cơ trong đó axit humic chiếm $39,1 \%$ và axit fulvic chiếm $30,2 \%$.

\subsubsection{Bố trí thí nghiệm}

Thí nghiệm hai yếu tố được bố trí theo kiểu hoàn toàn ngẫu nhiên gồm ba độ dày giá thể $(25$ $\mathrm{cm}, 20 \mathrm{~cm}$ và $15 \mathrm{~cm})$ và ba khoảng cách trồng $(20$ $\times 20 \mathrm{~cm}, 20 \times 15 \mathrm{~cm}$ và $20 \times 10 \mathrm{~cm}$ ) với ba lần lặp lại.

Số ô thí nghiệm là $9 \times 3=27$ ô và diện tích thí nghiệm là $27 \hat{\mathrm{o}} \times 3 \mathrm{~m}^{2} / \mathrm{o}=81 \mathrm{~m}^{2}$.

Giá thể được cho vào bồn với các độ dày tương ứng là $25 \mathrm{~cm}, 20 \mathrm{~cm}$ và $15 \mathrm{~cm}$. Có 3 khoảng cách trồng: $20 \times 20 \mathrm{~cm}, 20 \times 15 \mathrm{~cm}$ và $20 \times 10 \mathrm{~cm}$. Cây thí nghiệm được theo dõi trong suốt bốn đợt thu hoạch (30 ngày thu hoạch một lần) và được bổ sung phân bón lá hữu cơ DS80 với liều lượng $120 \mathrm{~mL} / 3 \mathrm{~m}^{2}$ (nồng độ $300 \mathrm{ppm}$ ) 10 ngày/lần. Khi thu hoạch, cành đạt chuẩn (có ít nhất 4 cặp lá thật) được cắt cách bề mặt giá thể $1 \mathrm{~cm}$.

Các chỉ tiêu theo dõi bao gồm: Số cành (cành/cây), chiều dài cành $(\mathrm{cm})$, số cặp lá trên cành (cặp lá/cành), trọng lượng tươi của cây (g/cây) và năng suất thực thu $\left(\mathrm{kg} / 1000 \mathrm{~m}^{2}\right)$.

Số liệu thu thập được tính toán bằng phần mềm Microsoft Excel; phân tích ANOVA, xếp hạng Duncan ở mức $\alpha=0,01$ hoặc $\alpha=0,05$ bằng chương trình SAS 9.1.

\section{Kết Quả và Thảo Luận}

Kết quả ở Bảng 1 cho thấy giá thể có độ chua gần trung tính và không bị nhiễm mặn (Slavich \& Petterson, 1993). Hàm lượng dinh dưỡng đạm và lân tổng số trong các công thức giá thể được đánh giá ở mức tương đối cao và hàm lượng kali tổng số ở mức trung bình (Rayment \& Lyons, 2011). Tỉ lệ $\mathrm{C} / \mathrm{N}(20,69)$ cũng cho thấy giá thể đang trong giai đoạn phân hủy chậm. Bên cạnh đó, giá thể có tính chất khá xốp (độ rỗng $=63,37 \%$ ), độ ẩm trung bình (43,76\%). Nhìn chung, tính chất giá thể phù hợp với sinh trưởng của cây rau quế vị.

\section{1. Ảnh hưởng của độ dày giá thể và khoảng cách trồng đến số cành trên cây quế vị}

Sự khác biệt về số cành trên cây quế vị rất có ý nghĩa thống kê dưới ảnh hưởng của các độ dày giá thể và khoảng cách trồng khác nhau (Bảng 2). 
Bảng 1. Tính chất của giá thể sử dụng trong thí nghiệm

\begin{tabular}{lccl}
\hline Chỉ tiêu & Đơn vị & Kết quả & Phương pháp phân tích \\
\hline $\mathrm{pH}_{\mathrm{H}_{2} \mathrm{O}}(1: 5)$ & & 6,87 & $\mathrm{pH}$ meter \\
$\mathrm{pH} \mathrm{KCl}_{\mathrm{Kl}}(1: 5)$ & & 6,05 & $\mathrm{pH}$ meter \\
$\mathrm{EC}(1: 5)$ & $\mathrm{mS} / \mathrm{cm}$ & 2,37 & EC meter \\
Độ rỗng & $\%$ & 63,37 & Sổ tay phân tích \\
Ầm độ & $\%$ & 43,76 & Phương pháp sây \\
$\mathrm{C}$ & $\%$ & 26,28 & Phương pháp Tiurin \\
$\mathrm{N}$ & $\%$ & 1,27 & Phương pháp Kjelhdal \\
$\mathrm{C} / \mathrm{N}$ & & 20,69 & \\
$\mathrm{P}_{2} \mathrm{O}_{5}$ & $\%$ & 0,81 & Phương pháp so màu \\
$\mathrm{K}_{2} \mathrm{O}$ & $\%$ & 1,19 & Phương pháp quang kế ngọn lửa \\
\hline
\end{tabular}

Độ dày giá thể $20 \mathrm{~cm}$ cho số cành trên cây quế vị cao nhất qua các đợt thu hoạch $(17,3$ cành/cây ở đợt 4). Trong khi giá thể có độ dày $25 \mathrm{~cm}$ cho số cành của cây quế vị thấp nhất qua các đợt (đợt 4: 10,5 cành/cây). Điều này có thể lý giải dựa vào sự bốc hơi nước ở độ dày giá thể này nhanh, làm cho bề mặt giá thể có ẩm độ thấp hơn so với các giá thể có độ dày 15 và $20 \mathrm{~cm}$. Trồng cây quế vị với khoảng cách $20 \times 15 \mathrm{~cm}$ cho số cành trên cây cao nhất, với 10,6 - 18,4 cành/cây. Nhìn chung, ở khoảng cách trồng này, cây có đủ không gian thích hợp để gia tăng số cành trên cây. Khoảng cách trồng $20 \times 10 \mathrm{~cm}$ có mật độ cây dày hơn ảnh hưởng đến việc ra cành mới; trong khi trồng với khoảng cách $20 \times 20 \mathrm{~cm}$ cho mật độ cây thưa làm cho giá thể nhanh mất nước làm giảm số cành trên cây quế vị.

Tương tác giữa độ dày giá thể và khoảng cách trồng có ảnh hưởng đến số cành trên cây quế vị bắt đầu từ đợt 2 . Tương tác giữa hai độ dày giá thể $20 \mathrm{~cm}$ kết hợp với khoảng cách trồng $20 \times$ $15 \mathrm{~cm}$ cho số cành trên cây quế vị nhiều nhất qua các đợt (đợt 4: 22,6 cành/cây), khác biệt rất có ý nghĩa thống kê so với các nghiệm thức còn lại. Khi trồng cây quế vị trên giá thể có độ dày $25 \mathrm{~cm}$ kết hợp khoảng cách $20 \times 20 \mathrm{~cm}$ cho kết quả số cành ít nhất và giảm liên tục qua các đợt thu hoạch từ 10,1 cành/cây (đợt 1 ) xuống còn 7,4 cành/cây (đợt 4). Tổ hợp này nhìn chung không phù hợp cho sự sinh trưởng của cây quế vị vì khả năng giữ ẩm kém hơn so với các tổ hợp khác trong thí nghiệm.

\section{2. Ảnh hưởng của đô dày giá thể và khoảng cách trồng đến chiều dài cành cây quế vị}

Dưới ảnh hưởng của độ dày giá thể và khoảng cách trồng, sự khác biệt về chiều dài cành của cây quế vị rất có ý nghĩa thống kê (Bảng 3). Khi so sánh trung bình độ dày giá thể, cây quế vị cho kết quả chiều dài cành cao nhất khi trồng trên giá thể có độ dày 15 và $20 \mathrm{~cm}$ (đợt 4: 16,3 và 15,0 $\mathrm{cm}$ ) và thấp nhất ở giá thể có độ dày $25 \mathrm{~cm}$ (đợt 4: 10,0 cm). Trung bình khoảng cách trồng cho kết quả cao nhất về chiều dài cành quế vị là 20 x $15 \mathrm{~cm}$ và $20 \times 10 \mathrm{~cm}$ (đợt 4: 15,2 và $14,9 \mathrm{~cm}$ ); khoảng cách trồng $20 \times 20 \mathrm{~cm}$ cho chiều dài cành thấp nhất (đợt 4: 11,2 cm). Như vậy, khi trồng quế vị với khoảng cách thưa $(20 \times 20 \mathrm{~cm})$, sự mất nước do mật độ cây thấp dẫn đến hạn chế về chiều dài cành.

Tương tự như số cành trên cây, chiều dài cành của cây quế vị bị ảnh hưởng bởi tổ hợp độ dày giá thể và khoảng cách trồng bắt đầu ở đợt 2 . Tương tác giữa giá thể có độ dày $20 \mathrm{~cm}$ kết hợp với khoảng cách trồng $20 \times 15 \mathrm{~cm}$ cho cây quế vị có chiều dài cành cao nhất qua các đợt 2 và 3 (lần lượt là 14,0 và $16,0 \mathrm{~cm}$ ). Tuy nhiên ở đợt 4 , tương tác giữa độ dày giá thể $15 \mathrm{~cm}$ kết hợp với khoảng cách trồng $20 \times 15 \mathrm{~cm}$ cho chiều dài cành vượt trội nhất với $17,7 \mathrm{~cm} /$ cành, khác biệt rất có ý nghĩa thống kê so với các nghiệm thức còn lại. Khi kết hợp giá thể có độ dày $25 \mathrm{~cm}$ với khoảng cách trồng $20 \times 20 \mathrm{~cm}$, chiều dài cành của cây quế vị là thấp nhất qua các đợt. 
Bảng 2. Ảnh hưởng của độ dày giá thể và khoảng cách trồng đến số cành (cành/cây) trên cây quế

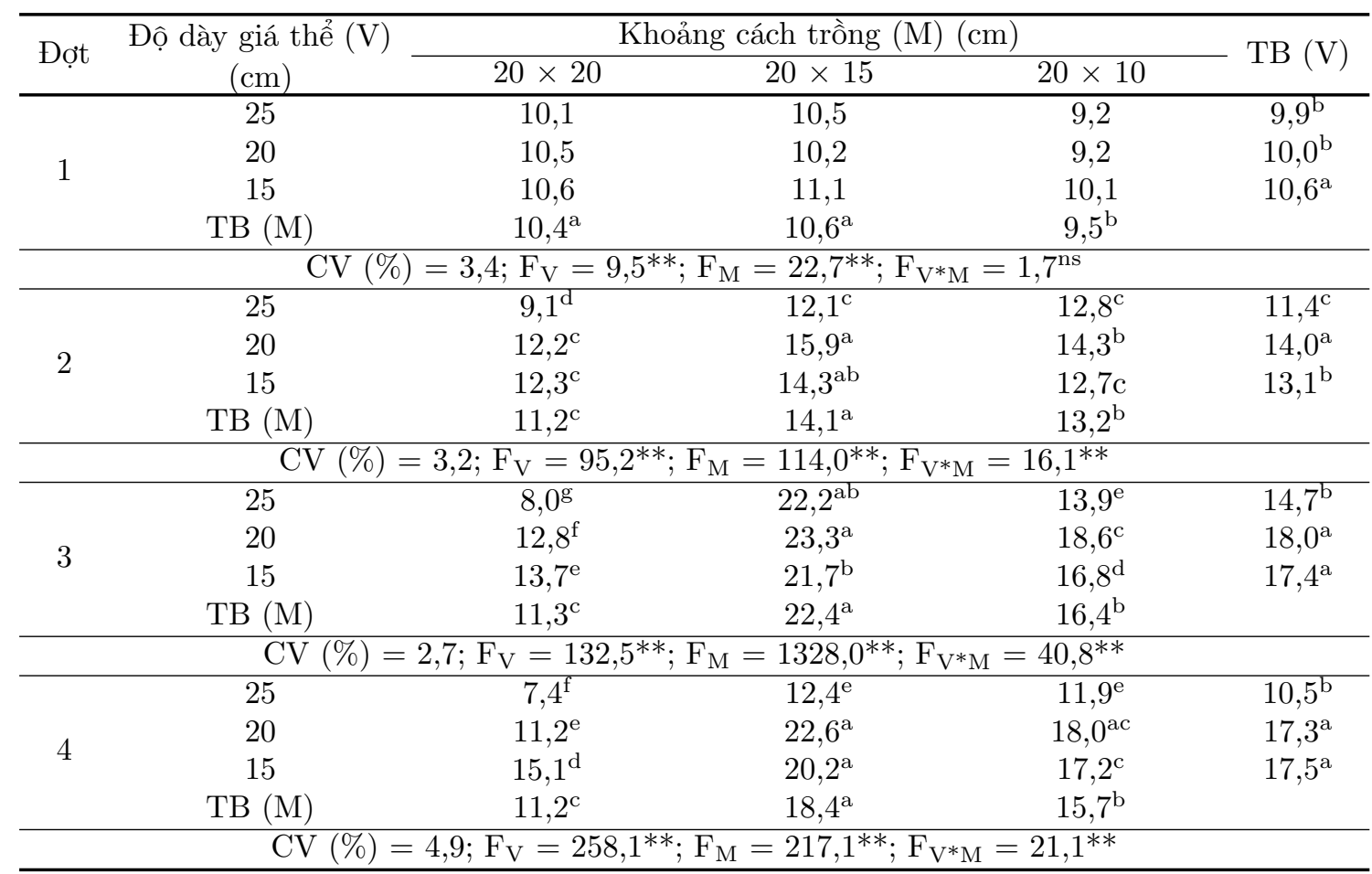

a-g Trong cùng một nhóm, các giá trị trung bình có cùng ký tự đi kèm khác biệt không có ý nghĩa thống kê $(\alpha=0,05) ;$ ns: không có khác biệt thống kê, **: khác biệt rất có ý nghĩa thống kê ở $\alpha=0,01$.

Bảng 3. Ảnh hưởng của độ dày giá thể và khoảng cách trồng đến chiều dài cành $(\mathrm{cm})$ cây quế

\begin{tabular}{|c|c|c|c|c|c|}
\hline \multirow{2}{*}{ Đợt } & \multirow{2}{*}{$\begin{array}{c}\text { Độ dày giá thể (V) } \\
(\mathrm{cm})\end{array}$} & \multicolumn{3}{|c|}{ Khoảng cách trồng $(\mathrm{M})(\mathrm{cm})$} & \multirow{2}{*}{$\mathrm{TB}(\mathrm{V})$} \\
\hline & & $20 \times 20$ & $20 \times 15$ & $20 \times 10$ & \\
\hline \multirow{4}{*}{1} & 25 & $\overline{5,1}$ & 6,7 & 6,4 & $6,1^{\mathrm{b}}$ \\
\hline & 20 & 6,8 & 7,4 & 7,6 & $7,3^{\mathrm{a}}$ \\
\hline & 15 & 6,1 & 7,8 & 7,4 & $7,2^{\mathrm{a}}$ \\
\hline & $\mathrm{TB}(\mathrm{M})$ & $6,1^{\mathrm{b}}$ & $7,3^{\mathrm{a}}$ & $7,1^{\mathrm{a}}$ & \\
\hline \multicolumn{6}{|c|}{$\mathrm{CV}(\%)=4,7 ; \mathrm{F}_{\mathrm{V}}=37,9^{* *} ; \mathrm{F}_{\mathrm{M}}=40,5^{* *} ; \mathrm{F}_{\mathrm{V}^{*} \mathrm{M}}=2,7^{\mathrm{ns}}$} \\
\hline \multirow{4}{*}{2} & 25 & $9,2^{\mathrm{c}}$ & $9,4^{\mathrm{c}}$ & $11,4^{\mathrm{b}}$ & $10,0^{\mathrm{b}}$ \\
\hline & 20 & $10,2^{\mathrm{c}}$ & $14,0^{\mathrm{a}}$ & $12,9^{\mathrm{a}}$ & $12,4^{\mathrm{a}}$ \\
\hline & 15 & $9,9^{\mathrm{c}}$ & $14,0^{\mathrm{a}}$ & $13,1^{\mathrm{a}}$ & $12,3^{\mathrm{a}}$ \\
\hline & $\mathrm{TB}(\mathrm{M})$ & $9,8^{\mathrm{b}}$ & $12,5^{\mathrm{a}}$ & $12,4^{\mathrm{a}}$ & \\
\hline \multicolumn{6}{|c|}{$\mathrm{CV}(\%)=4,1 ; \mathrm{F}_{\mathrm{V}}=74,8^{* *} ; \mathrm{F}_{\mathrm{M}}=98,9^{* *} ; \mathrm{F}_{\mathrm{V}^{*} \mathrm{M}}=17,1^{* *}$} \\
\hline \multirow{4}{*}{3} & 25 & $8,0^{\mathrm{f}}$ & $10,7^{\mathrm{e}}$ & $11,8^{\mathrm{de}}$ & $10,2^{\mathrm{b}}$ \\
\hline & 20 & $11,1^{\mathrm{e}}$ & $16,0^{\mathrm{a}}$ & $14,4^{\mathrm{b}}$ & $13,8^{\mathrm{a}}$ \\
\hline & 15 & $12,9^{\mathrm{cd}}$ & $15,8^{\mathrm{a}}$ & $14,0^{\mathrm{bc}}$ & $14,3^{\mathrm{a}}$ \\
\hline & $\mathrm{TB}(\mathrm{M})$ & $10,7^{\mathrm{c}}$ & $14,2^{\mathrm{a}}$ & $13,4^{\mathrm{b}}$ & \\
\hline \multicolumn{6}{|c|}{$\mathrm{CV}(\%)=2,7 ; \mathrm{F}_{\mathrm{V}}=163,1^{* *} ; \mathrm{F}_{\mathrm{M}}=109,2^{* *} ; \mathrm{F}_{\mathrm{V}^{*} \mathrm{M}}=10,9^{* *}$} \\
\hline \multirow{4}{*}{4} & 25 & $5,9^{\mathrm{f}}$ & $11,3^{\mathrm{e}}$ & $12,8^{\mathrm{d}}$ & $10,0^{\mathrm{C}}$ \\
\hline & 20 & $12,4^{\mathrm{de}}$ & $16,6 \mathrm{~b}$ & $16,0^{\mathrm{bc}}$ & $15,0^{\mathrm{b}}$ \\
\hline & 15 & $15,3^{\mathrm{c}}$ & $17,7^{\mathrm{a}}$ & $15,8^{\mathrm{bc}}$ & $16,3^{\mathrm{a}}$ \\
\hline & $\mathrm{TB}(\mathrm{M})$ & $11,2^{\mathrm{b}}$ & $15,2^{\mathrm{a}}$ & $14,9^{\mathrm{a}}$ & \\
\hline
\end{tabular}

a-f Trong cùng một nhóm, các giá trị trung bình có cùng ký tự đi kèm khác biệt không có ý nghĩa thống kê ( $\alpha=0,05$ ); ns: không có khác biệt thống kê, **: khác biệt rất có ý nghĩa thống kê ở $\alpha=0,01$. 


\section{3. Ảnh hưởng của độ dày giá thể và khoảng cách trồng đến số cặp lá trên cành cây quế vị}

Kết quả ở Bảng 4 cho thấy, trong hai đợt thu hoạch đầu tiên số cặp lá trên cành của cây quế vị không khác biệt thống kê dưới ảnh hưởng tương tác của độ dày giá thể và khoảng cách trồng. Ở hai đợt này, số cặp lá trên cành của cây quế vị được quyết định bởi khoảng cách trồng. Số cặp lá trên cành của cây quế vị thấp nhất khi trồng ở khoảng cách $20 \times 20 \mathrm{~cm}$ (lần lượt là 4,6 và 5,1 cặp lá/cành) và cao nhất ở khoảng cách $20 \times 10$ cm (ở cả hai đợt là 5,5 cặp lá/cành). Điều này cho thấy, khi trồng dày, bề mặt giá thể được che phủ tốt hơn nên ít bị tác động bởi nhiệt độ của khu thí nghiệm, do đó cây sinh trưởng tốt và cho số lá nhiều hơn.

Ở đợt 3 và đợt 4 , sự khác biệt về số cặp lá trên cành của cây quế vị ở các nghiệm rất có ý nghĩa thống kê (Bảng 4). Cây quế vị được trồng trên giá thể có độ dày $25 \mathrm{~cm}$ kết hợp với khoảng cách $20 \times 20 \mathrm{~cm}$ có số cặp lá trên cành thấp nhất ở cả bốn đợt thu hoạch (tương ứng 4,5, 4,8, 4,9 và 4,0 cặp lá/cành). Không có sự khác nhau về số cặp lá trên cành của cây ở các tổ hợp độ dày giá thể và khoảng cách trồng còn lại trong thí nghiệm, dao động trong khoảng 5,6 - 6,0 cặp lá/cành ở đợt 3 và 5,1 - 5,8 cặp lá/cành ở đợt 4 .

\section{4. Ảnh hưởng của độ dày giá thể và khoảng cách trồng đến trọng lượng tươi cây quế vị}

Kết quả từ Bảng 5 cho thấy, độ dày giá thể có ảnh hưởng đến trọng lượng tươi của cây quế vị do tác động trực tiếp đến số cành trên cây cũng như chiều dài cành hay số cặp lá trên cành. Khi so sánh trung bình độ dày giá thể, ở đợt 4 , giá thể có độ dày $20 \mathrm{~cm}$ cho trọng lượng tươi của cây quế vị cao nhất (53,1 g/cây) nhưng không khác biệt thống kê so với độ dày giá thể $15 \mathrm{~cm}(51,3$ $\mathrm{g} /$ cây). Trong khi đó, độ dày giá thể $25 \mathrm{~cm}$ cho kết quả trọng lượng tươi của cây quế vị thấp nhất là $29,0 \mathrm{~g} /$ cây.

Trồng cây quế vị với khoảng cách 20 x $15 \mathrm{~cm}$ cho kết quả trọng lượng tươi của cây cao nhất qua các đợt thu hoạch (đợt 4: 56,0 g/cây), khác biệt rất có ý nghĩa thống kê so với các khoảng cách trồng còn lại. Cây quế vị được trồng với khoảng cách hợp lý giúp năng suất cá thể đạt cao nhất. Cây quế vị được trồng với khoảng cách thưa hơn
$(20 \times 20 \mathrm{~cm})$ cho kết quả trọng lượng tươi của cây thấp nhất (đợt 4: 30,2 g/cây).

Tương tác giữa độ dày giá thể và khoảng cách trồng cũng tạo nên sự khác biệt rất có ý nghĩa thống kê về trọng lượng tươi của cây quế vị (Bảng 5). Tổ hợp giữa giá thể có độ dày 15 và $20 \mathrm{~cm}$ kết hợp với khoảng cách trồng $20 \times 15 \mathrm{~cm}$ lần lượt cho trọng lượng tươi của cây quế vị cao nhất qua các đợt thu hoạch, kết quả được ghi nhận ở đợt 4 lần lượt là 65,1 và $66,7 \mathrm{~g} /$ cây. Khi trồng cây quế vị trên giá thể có độ dày $25 \mathrm{~cm}$ kết hợp với khoảng cách trồng $20 \times 20 \mathrm{~cm}$ cho kết quả trọng lượng tươi của cây thấp nhất và giảm liên tục trong bốn đợt thu hoạch 24,7 - 13,6 g/cây.

Hình 1 cho thấy cành của cây quế vị tại độ dày giá thể $25 \mathrm{~cm}$ và khoảng cách trồng $20 \times 20 \mathrm{~cm}$ có chiều dài cành ngắn và số cặp lá trên cành thấp hơn so với các nghiệm thức còn lại. Trong khi đó, cây quế vị được trồng trên giá thể có độ dày $20 \mathrm{~cm}$ kết hợp với khoảng cách trồng $20 \times 15$ hoặc $20 \times 10 \mathrm{~cm}$ cho chiều dài cành và số cặp lá trên cành nhiều hơn. Ở khoảng cách trồng thưa $(20 \times 20 \mathrm{~cm})$, quá trình bốc hơi nước ở bề mặt giá thể diễn ra nhanh, do đó ảnh hưởng đến quá trình sinh trưởng của cây quế vị.

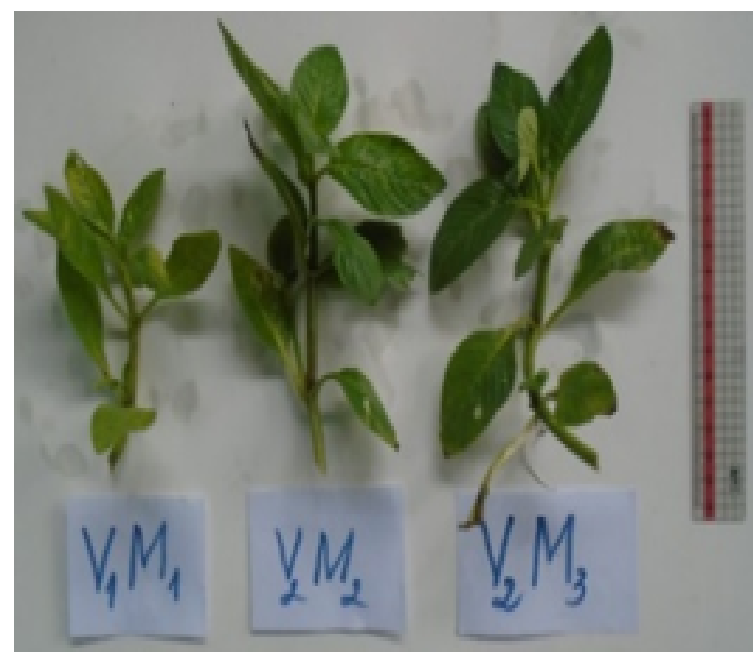

Hình 1. Cành quế vị khi được trồng ở các độ dày giá thể và khoảng cách khác nhau (thu hoạch đợt 3).

$\mathrm{V}_{1} \mathrm{M}_{1}$ : Độ dày giá thể $25 \mathrm{~cm}$, khoảng cách trồng $20 \times 20 \mathrm{~cm}$.

$\mathrm{V}_{2} \mathrm{M}_{2}$ : Độ dày giá thể $20 \mathrm{~cm}$, khoảng cách trồng $20 \times 15 \mathrm{~cm}$.

$\mathrm{V}_{2} \mathrm{M}_{3}$ : Độ dày giá thể $20 \mathrm{~cm}$, khoảng cách trồng $20 \times 10 \mathrm{~cm}$. 
Bảng 4. Ảnh hưởng của độ dày giá thể và khoảng cách trồng đến số cặp lá trên cành (cặp lá/cành) cây quế

\begin{tabular}{|c|c|c|c|c|c|}
\hline \multirow{2}{*}{ Đợt } & \multirow{2}{*}{$\begin{array}{c}\text { Độ dày giá thể }(\mathrm{V}) \\
(\mathrm{cm})\end{array}$} & \multicolumn{3}{|c|}{ Khoảng cách trồng $(\mathrm{M})(\mathrm{cm})$} & \multirow{2}{*}{$\mathrm{TB}(\mathrm{V})$} \\
\hline & & $20 \times 20$ & $20 \times 15$ & $20 \times 10$ & \\
\hline \multirow{4}{*}{1} & 25 & 4,5 & 4,5 & 5,4 & 4,8 \\
\hline & 20 & 4,8 & 5,2 & 5,4 & 5,2 \\
\hline & 15 & 4,4 & 5,4 & 5,6 & 5,1 \\
\hline & $\mathrm{TB}(\mathrm{M})$ & $4,6^{\mathrm{b}}$ & $5,1^{\mathrm{ab}}$ & $5,5^{\mathrm{a}}$ & \\
\hline \multicolumn{6}{|c|}{$\mathrm{CV}(\%)=7,0 ; \mathrm{F}_{\mathrm{V}}=2,9^{\mathrm{ns}} ; \mathrm{F}_{\mathrm{M}}=14,0^{* *} ; \mathrm{F}_{\mathrm{V}^{*} \mathrm{M}}=1,8^{\mathrm{ns}}$} \\
\hline \multirow{4}{*}{2} & 25 & 4,8 & 5,1 & 5,5 & $5,1^{\mathrm{b}}$ \\
\hline & 20 & 5,1 & 5,4 & 5,4 & $5,3^{\mathrm{ab}}$ \\
\hline & 15 & 5,5 & 5,8 & 5,5 & $5,6^{\mathrm{a}}$ \\
\hline & $\mathrm{TB}(\mathrm{M})$ & $5,1^{\mathrm{b}}$ & $5,4^{\mathrm{a}}$ & $5,5^{\mathrm{a}}$ & \\
\hline \multicolumn{6}{|c|}{$\mathrm{CV}(\%)=4,6 ; \mathrm{F}_{\mathrm{V}}=8,2^{* *} ; \mathrm{F}_{\mathrm{M}}=4,4^{*} ; \mathrm{F}_{\mathrm{V}^{*} \mathrm{M}}=2,1^{\mathrm{ns}}$} \\
\hline \multirow{4}{*}{3} & 25 & $4,9^{\mathrm{b}}$ & $6,0^{\mathrm{a}}$ & $5,6^{\mathrm{a}}$ & $5,5^{\mathrm{b}}$ \\
\hline & 20 & $6,0^{\mathrm{a}}$ & $6,0^{\mathrm{a}}$ & $5,8^{\mathrm{a}}$ & $5,9^{\mathrm{a}}$ \\
\hline & 15 & $5,9^{\mathrm{a}}$ & $6,0^{\mathrm{a}}$ & $6,0^{\mathrm{a}}$ & $6,0^{\mathrm{a}}$ \\
\hline & TB (M) & $5,6^{\mathrm{b}}$ & $6,0^{\mathrm{a}}$ & $5,8^{\mathrm{ab}}$ & \\
\hline \multicolumn{6}{|c|}{$\mathrm{CV}(\%)=4,2 ; \mathrm{F}_{\mathrm{V}}=10,8^{* *} ; \mathrm{F}_{\mathrm{M}}=6,8^{* *} ; \mathrm{F}_{\mathrm{V} * \mathrm{M}}=4,8^{* *}$} \\
\hline \multirow{4}{*}{4} & 25 & $4,0^{\mathrm{c}}$ & $5,5^{\mathrm{a}}$ & $5,4^{\mathrm{a}}$ & $4,9^{\mathrm{b}}$ \\
\hline & 20 & $5,3^{\mathrm{a}}$ & $5,2^{\mathrm{a}}$ & $5,8^{\mathrm{a}}$ & $5,4^{\mathrm{a}}$ \\
\hline & 15 & $5,6^{\mathrm{a}}$ & $5,6^{\mathrm{a}}$ & $5,1^{\mathrm{a}}$ & $5,4^{\mathrm{a}}$ \\
\hline & TB $(\mathrm{M})$ & $4,9^{\mathrm{b}}$ & $5,7^{\mathrm{a}}$ & $5,4^{\mathrm{a}}$ & \\
\hline
\end{tabular}

a-c Trong cùng một nhóm, các giá trị trung bình có cùng ký tự đi kèm khác biệt không có ý nghĩa thống kê $(\alpha=0,05)$; ns: không có khác biệt thống kê, **: khác biệt rất có ý nghĩa thống kê ở $\alpha=0,01$.

Bảng 5. Ảnh hưởng của độ dày giá thể và khoảng cách trồng đến trọng lượng cây (g/cây) cây quế

\begin{tabular}{|c|c|c|c|c|c|}
\hline \multirow{2}{*}{ Đợt } & \multirow{2}{*}{$\begin{array}{l}\text { Độ dày giá thể }(\mathrm{V}) \\
(\mathrm{cm})\end{array}$} & \multicolumn{3}{|c|}{ Khoảng cách trồng $(\mathrm{M})(\mathrm{cm})$} & \multirow{2}{*}{$\mathrm{TB}(\mathrm{V})$} \\
\hline & & $20 \times 20$ & $20 \times 15$ & $20 \times 10$ & \\
\hline \multirow{4}{*}{1} & 25 & $24,7^{\mathrm{bc}}$ & $25,6^{\mathrm{bc}}$ & $23,3^{\mathrm{c}}$ & $24,6^{\mathrm{b}}$ \\
\hline & 20 & $25,7^{\mathrm{b}}$ & $30,02^{\mathrm{a}}$ & $23,1^{\mathrm{c}}$ & $26,3^{\mathrm{a}}$ \\
\hline & 15 & $25,4^{\mathrm{bc}}$ & $28,5^{\mathrm{a}}$ & $26,0^{\mathrm{b}}$ & $26,6^{\mathrm{q}}$ \\
\hline & $\mathrm{TB}(\mathrm{M})$ & $25,3^{\mathrm{b}}$ & $28,1^{\mathrm{q}}$ & $24,1^{\mathrm{b}}$ & \\
\hline \multicolumn{6}{|c|}{$\mathrm{CV}(\%)=3,8 ; \mathrm{F}_{\mathrm{V}}=11,9^{* *} ; \mathrm{F}_{\mathrm{M}}=38,1^{* *} ; \mathrm{F}_{\mathrm{V} * \mathrm{M}}=6,4^{* *}$} \\
\hline \multirow{4}{*}{2} & 25 & $19,7^{\mathrm{f}}$ & $29,0^{\mathrm{e}}$ & $31,5^{\mathrm{de}}$ & $26,8^{\mathrm{c}}$ \\
\hline & 20 & $30,5^{\mathrm{de}}$ & $44,5^{\mathrm{a}}$ & $36,5^{\mathrm{c}}$ & $37,2^{\mathrm{a}}$ \\
\hline & 15 & $32,7^{\mathrm{d}}$ & $39,7^{\mathrm{b}}$ & $33,4^{\mathrm{d}}$ & $35,3^{\mathrm{b}}$ \\
\hline & TB (M) & $27,7^{\mathrm{c}}$ & $37,7^{\mathrm{a}}$ & $33,8^{\mathrm{b}}$ & \\
\hline \multicolumn{6}{|c|}{$\mathrm{CV}(\%)=3,7 ; \mathrm{F}_{\mathrm{V}}=182,6^{* *} ; \mathrm{F}_{\mathrm{M}}=151,4^{* *} ; \mathrm{F}_{\mathrm{V}^{*} \mathrm{M}}=24,9^{* *}$} \\
\hline \multirow{4}{*}{3} & 25 & $19,7^{\mathrm{d}}$ & $68,1^{\mathrm{a}}$ & $38,8^{\mathrm{c}}$ & $42,2^{\mathrm{b}}$ \\
\hline & 20 & $37,1^{\mathrm{c}}$ & $71,4^{\mathrm{a}}$ & $52,1^{\mathrm{b}}$ & $53,6^{\mathrm{a}}$ \\
\hline & 15 & $39,3^{\mathrm{c}}$ & $68,9^{\mathrm{a}}$ & $48,7^{\mathrm{b}}$ & $52,3^{\mathrm{a}}$ \\
\hline & TB $(\mathrm{M})$ & $32,0^{\mathrm{c}}$ & $69,5^{\mathrm{a}}$ & $46,5^{\mathrm{b}}$ & \\
\hline \multicolumn{6}{|c|}{$\mathrm{CV}(\%)=3,6 ; \mathrm{F}_{\mathrm{V}}=109,6^{* *} ; \mathrm{F}_{\mathrm{M}}=1005,0^{* *} ; \mathrm{F}_{\mathrm{V}^{*} \mathrm{M}}=23,7^{* *}$} \\
\hline \multirow{4}{*}{4} & 25 & $13,6^{\mathrm{f}}$ & $36,0^{\mathrm{de}}$ & $37,2^{\mathrm{de}}$ & $29,0^{\mathrm{b}}$ \\
\hline & 20 & $34,7^{\mathrm{e}}$ & $66,7^{\mathrm{a}}$ & $57,8^{\mathrm{b}}$ & $53,1^{\mathrm{a}}$ \\
\hline & 15 & $42,4^{\text {cd }}$ & $65,1^{\mathrm{a}}$ & $46,3^{\mathrm{c}}$ & $51,3^{\mathrm{a}}$ \\
\hline & $\mathrm{TB}(\mathrm{M})$ & $30,2^{\mathrm{c}}$ & $56,0^{\mathrm{a}}$ & $47,1^{\mathrm{b}}$ & \\
\hline
\end{tabular}

a-f Trong cùng một nhóm, các giá trị trung bình có cùng ký tự đi kèm khác biệt không có ý nghĩa thống kê $(\alpha=0,05)$; **: khác biệt rất có ý nghĩa thống kê ở $\alpha=0,01$. 
Bảng 6. Ảnh hưởng của độ dày giá thể và khoảng cách trồng đến năng suất thực thu $(\mathrm{kg} / 1000$ m²) của cây quế

\begin{tabular}{|c|c|c|c|c|c|}
\hline \multirow{2}{*}{ Đợt } & \multirow{2}{*}{$\begin{array}{l}\text { Độ dày giá thể (V) } \\
(\mathrm{cm})\end{array}$} & \multicolumn{3}{|c|}{ Khoảng cách trồng (M) (cm) } & \multirow{2}{*}{$\mathrm{TB}(\mathrm{V})$} \\
\hline & & $20 \times 20$ & $20 \times 15$ & $20 \times 10$ & \\
\hline \multirow{4}{*}{1} & 25 & $433,4^{\mathrm{f}}$ & $627,9^{\mathrm{d}}$ & $899,9^{\mathrm{b}}$ & $653,7^{\mathrm{b}}$ \\
\hline & 20 & $557,0^{\mathrm{e}}$ & $714,1^{\mathrm{c}}$ & $946,0^{\mathrm{b}}$ & $739,0^{\mathrm{a}}$ \\
\hline & 15 & $518,7^{\mathrm{e}}$ & $754,3^{\mathrm{c}}$ & $1041,2^{\mathrm{a}}$ & $771,4^{\mathrm{a}}$ \\
\hline & $\mathrm{TB}(\mathrm{M})$ & $503,0^{\mathrm{c}}$ & $698,8^{\mathrm{b}}$ & $962,3^{\mathrm{a}}$ & \\
\hline \multicolumn{6}{|c|}{$\mathrm{CV}(\%)=4,2 ; \mathrm{F}_{\mathrm{V}}=36,0^{* *} ; \mathrm{F}_{\mathrm{M}}=518,6^{* *} ; \mathrm{F}_{\mathrm{V}^{*} \mathrm{M}}=3,7^{*}$} \\
\hline \multirow{4}{*}{2} & 25 & 416,2 & 695,1 & 980,7 & $697,3^{\mathrm{b}}$ \\
\hline & 20 & 566,8 & 1000,1 & 1202,5 & $923,1^{\mathrm{a}}$ \\
\hline & 15 & 574,0 & 901,7 & 1171,1 & $882,2^{\mathrm{a}}$ \\
\hline & $\mathrm{TB}(\mathrm{M})$ & $519,0^{\mathrm{c}}$ & $856,6^{\mathrm{b}}$ & $1118,1^{\mathrm{a}}$ & \\
\hline \multicolumn{6}{|c|}{$\mathrm{CV}(\%)=6,7 ; \mathrm{F}_{\mathrm{V}}=41,4^{* *} ; \mathrm{F}_{\mathrm{M}}=258,7^{* *} ; \mathrm{F}_{\mathrm{V}^{*} \mathrm{M}}=1,5^{\mathrm{ns}}$} \\
\hline \multirow{4}{*}{3} & 25 & $559,5^{\mathrm{f}}$ & $852,6^{\mathrm{e}}$ & $1266,5^{\mathrm{c}}$ & $950,5^{\mathrm{b}}$ \\
\hline & 20 & $1025,6^{\mathrm{d}}$ & $1862,1^{\mathrm{b}}$ & $2095,2^{\mathrm{a}}$ & $1603,3^{\mathrm{a}}$ \\
\hline & 15 & $836,8^{\mathrm{e}}$ & $1826,6^{\mathrm{b}}$ & $1909,6^{\mathrm{b}}$ & $1524,3^{\mathrm{a}}$ \\
\hline & $\mathrm{TB}(\mathrm{M})$ & $749,6^{\mathrm{c}}$ & $1571,4^{\mathrm{b}}$ & $1757,1^{\mathrm{a}}$ & \\
\hline \multicolumn{6}{|c|}{$\mathrm{CV}(\%)=3,8 ; \mathrm{F}_{\mathrm{V}}=439,2^{* *} ; \mathrm{F}_{\mathrm{M}}=994,6^{* *} ; \mathrm{F}_{\mathrm{V}^{*} \mathrm{M}}=34,2^{* *}$} \\
\hline \multirow{4}{*}{4} & 25 & $270,2^{\mathrm{g}}$ & $890,3^{\mathrm{d}}$ & $1133,4^{\mathrm{c}}$ & $764,6^{\mathrm{b}}$ \\
\hline & 20 & $482,2^{\mathrm{f}}$ & $1903,9^{\mathrm{b}}$ & $2170,9^{\mathrm{a}}$ & $1519,0^{\mathrm{a}}$ \\
\hline & 15 & $664,8^{\mathrm{e}}$ & $2075,4^{\mathrm{ab}}$ & $1947,3^{\mathrm{b}}$ & $1750,6^{\mathrm{a}}$ \\
\hline & $\mathrm{TB}(\mathrm{M})$ & $472,4^{\mathrm{c}}$ & $1623,2^{\mathrm{b}}$ & $1750,6^{\mathrm{a}}$ & \\
\hline & $\mathrm{CV}(\%)$ & $\mathrm{F}_{\mathrm{V}}=32$ & $=793,2^{* *}$ & $8,3^{* *}$ & \\
\hline \multirow{4}{*}{ Tổng } & 25 & $1679,3^{\mathrm{f}}$ & $2458,5^{\mathrm{e}}$ & $4280,5^{\mathrm{c}}$ & $3066,2^{\mathrm{b}}$ \\
\hline & 20 & $3238,8^{\mathrm{d}}$ & $5480,2^{\mathrm{b}}$ & $6414,6^{\mathrm{a}}$ & $4784,4^{\mathrm{a}}$ \\
\hline & 15 & $2594,2^{\mathrm{e}}$ & $5557,9^{\mathrm{b}}$ & $6069,2^{\mathrm{a}}$ & $4740,5^{\mathrm{a}}$ \\
\hline & $\mathrm{TB}(\mathrm{M})$ & $2244,0^{\mathrm{c}}$ & $4759,0^{\mathrm{b}}$ & $5588,1^{\mathrm{a}}$ & \\
\hline
\end{tabular}

${ }^{\text {a-g }}$ Trong cùng một nhóm, các giá trị trung bình có cùng ký tự đi kèm khác biệt không có ý nghĩa thống kê ( $\alpha=0,05$ ); ns: không có khác biệt thống kê; **: khác biệt rất có ý nghĩa thống kê ở $\alpha=0,01$.

\section{5. Ảnh hưởng của độ dày giá thể và khoảng cách trồng đến năng suất thực thu của cây quế vị}

Sự khác biệt về năng suất thực thu của cây quế vị dưới ảnh hưởng của các độ dày giá thể rất có ý nghĩa thống kê (Bảng 6). Ở tất cả các đợt thu hoạch, hai độ dày giá thể 15 và $20 \mathrm{~cm}$ cho kết quả cây quế vị có năng suất thực thu cao nhất; tổng năng suất thực thu ở hai độ dày giá thể này lần lượt là 4740,5 và $4784,4 \mathrm{~kg} / 1000 \mathrm{~m}^{2}$. Trung bình độ dày giá thể $25 \mathrm{~cm}$ cho kết quả năng suất thực thu thấp nhất; tổng năng suất thực thu đạt $3066,2 \mathrm{~kg} / 1000 \mathrm{~m}^{2}$.

Năng suất thực thu của cây quế vị cho kết quả cao nhất ở các nghiệm thức có khoảng cách trồng $20 \times 10 \mathrm{~cm}$ do các nghiệm thức này có mật độ cây dày nhất $\left(50\right.$ cây $\left./ \mathrm{m}^{2}\right)$. Về trung bình khoảng cách trồng, tổng năng suất thực thu của cây quế vị khi được trồng ở khoảng cách $20 \times 10 \mathrm{~cm}$ đạt $5588,1 \mathrm{~kg} / 1000 \mathrm{~m}^{2}$. Năng suất thực thu của cây quế vị thấp nhất khi được trồng ở khoảng cách trồng $20 \times 20 \mathrm{~cm}$ với tổng năng suất thực thu đạt $2244,0 \mathrm{~kg} / 1000 \mathrm{~m}^{2}$.

Tương tác giữa độ dày giá thể và khoảng cách trồng có ảnh hưởng đến năng suất thực thu của cây quế vị. Các tổ hợp độ dày giá thể $15,20 \mathrm{~cm}$ kết hợp với khoảng cách trồng $20 \times 10 \mathrm{~cm}$ lần lượt cho năng suất thực thu của cây quế vị cao nhất qua bốn đợt thu hoạch. Do đó, tổng năng suất thực thu của cây quế vị ở các tổ hợp này cũng đạt cao nhất. Cụ thể, tổ hợp độ dày giá thể $15 \mathrm{~cm}$ kết hợp với khoảng cách trồng $20 \times 10$ cm cho cây quế vị có tổng năng suất thực thu đạt $6069,2 \mathrm{~kg} / 1000 \mathrm{~m}^{2}$; tổ hợp độ dày giá thể 20 $\mathrm{cm}$ kết hợp với khoảng cách trồng $20 \times 10 \mathrm{~cm}$ là $6414,6 \mathrm{~kg} / 1000 \mathrm{~m}^{2}$. Nhìn chung, trọng lượng tươi của cây quế vị khi được trồng trên giá thể có độ 
dày $20 \mathrm{~cm}$ kết hợp với khoảng cách trồng $20 \times$ $10 \mathrm{~cm}$ tăng liên tục qua bốn đợt thu hoạch dẫn đến sự gia tăng về năng suất thực thu. Kết quả từ Bảng 6 cho thấy khi kết hợp độ dày giá thể 25 $\mathrm{cm}$ với khoảng cách trồng $20 \times 20 \mathrm{~cm}$, cây quế vị có năng suất thực thu qua bốn đợt thu hoạch và tổng năng suất thực thu $\left(1679,3 \mathrm{~kg} / 1000 \mathrm{~m}^{2}\right)$ thấp nhất.

\section{Kết Luận}

Độ dày giá thể $20 \mathrm{~cm}$ kết hợp với khoảng cách trồng $20 \times 15 \mathrm{~cm}$ cho kết quả cây quế vị có số cành (đợt 4: 22,6 cành/cây) và trọng lượng tươi (đợt 4: 66,7 g/cây) cao hơn so với các nghiệm thức còn lại trong thí nghiệm. Độ dày giá thể 20 $\mathrm{cm}$ kết hợp với khoảng cách trồng $20 \times 10 \mathrm{~cm}$ cho cây quế vị có năng suất thực thu cao nhất qua bốn đợt thu hoạch và tổng năng suất thực thu dạt $6414,6 \mathrm{~kg} / 1000 \mathrm{~m}^{2}$.

\section{Tài Liệu Tham Khảo (References)}

Acharya, R., Padiya, R. H., Patel, E. D., Harisha, C. R., \& Shukla V. J. (2014). Microbial evaluation of Limnophila rugosa (Roth) Merr. leaf. An International Quarterly Journal of Research in Ayurveda 35(2), 207-210.

Nguyen, H. V. (2015). Effects of planting density and fertilizer application level on growth and yield of Te Rau rice variety in Phong Tho, Lai Chau (Unpublished master's thesis). Thai Nguyen University of Agriculture and Forestry, Thai Nguyen, Vietnam.
Olle, M., Ngouajio, M., \& Siomos, A. (2012). Vegetable quality and productivity as inflenced by growing medium: a review. Agriculture 99(4), 399-408.

Pham, L. V. (2009). Measures to prevent pests of agricultural crops. Ha Noi, Vietnam: Agricultural Publishing House.

Rayment, G. E., \& Lyons, D. J. (2011). Soil chemical methods - Australasia. Collingwood, Australia: CSIRO Publishing.

Samith, A., Yasin, A., \& Azmi, A.Y. (2010). The influence of plant spacing on yield and fruit nitrate concentration of greenhouse cucumber (Cucumis sativus L.). Jordan Journal of Agricultural Sciences 6(4), 527-533.

Slavich, P. G., \& Petterson, G. H. (1993). Estimating the critical conductivity of saturated paste extracts from 1:5 soil:water suspensions and texture. Australian Journal of Soil Research 31(1), 73-81.

Tanaka, Y., \& Nguyen, V. K. (2007). Edible wild plants of Vietnam - The bountiful garden. Bangkok, Thailand: Orchid Press.

Vo, A. V., Nguyen, H. M., \& Nguyen, C. M. (1998). Integrated pest management on crops. Ha Noi, Vietnam: Agricultural Publishing House. 